\title{
HUBUNGAN ASSERTIVENESS TERHADAP SELF ESTEEM PADA MAHASISWA KEPERAWATAN DI STIKES PAMENANG PARE KEDIRI
}

\section{THE CORRELATION ASSERTIVENESS TO SELF ESTEEM NURSING STUDENTS IN DEPARTMENT OF NURSING PAMENANG HEALTH INSTITUTE PARE KEDIRI}

\author{
Erwin Yektiningsih ${ }^{1}$ \\ ${ }^{1}$ Sekolah Tinggi Ilmu Kesehatan Pamenang \\ J1. 'Soekarno Hatta No. 15 Pare Kediri \\ *Korespondensi Penulis : erwiny.parefortune@gmail.com
}

\begin{abstract}
Abstrak
Latar Belakang : Peningkatan SDM keperawatan sejak berada di institusi pendidikan perlu mengembangkan kemampuan soft skill seperti assertive yang berpengaruh terhadap konsep diri menjadi perawat profesional. Adapun salah satu komponen konsep diri adalah self esteem perawat yang dapat digambarkan sebagai informasi dan keyakinan bahwa perawat memiliki tentang tugas, nilai, dan perilaku untuk pengembangan nilai-nilai profesional. Tujuan: Penelitian ini bertujuan mengatahui perilaku assertive dan Self Esteem pada mahasiswa keperawatan di STIKes Pamenang Pare Kediri pada tahun 2020. Methode: Penelitian ini adalah analitik digunakan pendekatan cross sectional dengan spearman-rho. Populasi adalah mahasiswa keperawatan 119 dan sampel 40 dengan teknik random sampling. Adapun Instrument penelitian ini kuesioner baku adalah Rathus Assertiveness Schedule (RAS) dan Rosenberg Self Esteem (RSE). Hasil: Hasil penelitian ini adalah terdapat hubungan signifikan yang cukup kuat dengan nilai korelasi positive antara assertive dengan self-esteem pada mahasiswa di STIKes Pamenang Pare, dikarenakan mahasiswa keperawatan yang berperilaku asertif tinggi cenderung mempunyai harga diri tinggi, sehingga sangat berkaitan erat dengan kelancaran selama menjalani masa studi di pendidikan keperawatan yang menghasilkan lulusan perawat yang kompeten dan profesional. Kesimpulan: Self esteem merupakan sejauh mana individu menilai dirinya yang memiliki kemampuan, keberartian, berharga, dan kompetensi yang dapat mempengaruhi perawat bertindak profesional sangat berkaitan dengan perilaku asertive. Sehingga semenjak di pendidikan perlu di siapkan pengelolaan assertiveness yang efektif untuk peningkatan low self esteem pada mahasiswa keperawatan.
\end{abstract}

Keyword: Mahasiswa, Perawat, Assertiveness, Self steem

\begin{abstract}
Introduction: Improvement of nursing human resources since they are in educational institutions needs to develop soft skills such as assertive which affect the self-concept of becoming professional nurses. One component of the self-concept is nurses' self-esteem which can be described as information and beliefs that nurses have about duties, values, and behaviors for the development of professional values. Aims: This aims of research identified assertive behavior to self esteem in nursing students in Department of nursing Pamenang Health Institute Pare Kediri East Jawa in 2020. Methods: This study used analytic cross sectional approach with spearman-rho. The population nursing students were 119 and samples were 40 with random sampling techniques. This research the instruments were Rathus Assertiveness Schedule (RAS) and Rosenberg Self Esteem (RSE). Results: The results of this research was a significant and positive corelation between assertive and self-esteem in nursing students in Department of nursing Pamenang Health Institute Pare Kediri, because nursing students with high assertive category behavior tend to have high self-esteem category, so its were closely related to fluency while undergoing a period to study in nursing education that produces competent and professional nurse graduates. Conclusion: Selfesteem was the extent to which individuals assess themselves who had abilities, meaningfulness, worth, and competence that can influence nurses to act professionally were closely related to
\end{abstract}

Submitted : 28 April 2020, Accepted : 18 Mei 2020

Wesite : jurnal.stikespamenang.ac.di | Email :jurnal.pamenang@gmail.com 
asertive behavior. So since in education it was necessary to prepare effective assertiveness management to increase low self esteem in nursing students.

Keywords: students, nurses, assertiveness, self esteem

\section{Pendahuluan}

Salah satu aspek penting dalam pembangunan kesehatan di Indonesia dengan tersedianya sumber daya manusia (SDM) tenaga kesehatan, merupakan tuntutan jaman supaya berkompetisi di era (MEA) Masyarakat Ekonomi ASEAN (Ristekdikti, 2017). Maka profesi keperawatan perlu mengembangkan konsep diri perawat profesional yang merupakan masalah penting dalam pendidikan keperawatan, dimana konsep diri perawat dapat digambarkan sebagai informasi dan keyakinan bahwa perawat memiliki tentang tugas, nilai, dan perilaku mereka yang membantu mengembangkan nilai-nilai profesional (Ware, 2008 dalam Parandavar, Rahmanian, \& Badiyepeymaie Jahromi, 2015).

Self-esteem dan perilaku assertive berkaitan erat dengan tindakan profesional perawat berkaitan dengan aktivitas sehari-hari yang berkaitan dengan interaksi dengan pasien,rekan sejawat, dokter dan staf yang lainnya bekerja secara tim (S. K. Maheshwari, 2015). Yang mana Assertive merupakan salah satu skill yang paling penting yang harus di miliki perawat dalam dunia kerja seperti kemampuan dalam memanagemant waktu secara efisien, berkaitan dengan meningkatnya self-esteem serta mengelola problem solving secara efektif (Mohamed, Abd El-hammed and Thabet, 2016).

Mahasiswa perawat perilakunya mengalami perubahan karena adanya penambahan pengetahuan keterampilan serta perubahan sikap mental, tetapi sistem pendidikan orang dewasa tidak cukup hanya memberi tambahan pengetahuan, tetapi harus dibekali rasa percaya. Peningkatan pengetahuan disertai kepercayaan diri kuat akan mampu melahirkan perubahan ke arah positif berupa pembaharuan baik fisik maupun mental secara nyata, menyeluruh dan berkesinambungan (Nursalam. Effendi, 2014). Mahasiswa selama mengikuti proses pendidikan keperawatan berkaitan kesehatan manusia, misalnya mengalami beragam tugas sulit, sering menyaksikan situasi penderitaan, rasa sakit dan kematian, itu merupakan faktor tidak langsung mempengaruhi hubungan interpersonal dan harga diri pada mahasiswa keperawatan. Gabungan dari kehidupan yang sibuk, tekanan dan stres, semakin umum dalam kehidupan sehari-hari mahasiswa, itu berpengaruh pada harga diri rendah jika tidak di tangani secepatnya bisa menjadi masalah serius (Chaves Cássia Lopes et al., 2012). Bila individu tidak bisa asertif maka dalam melakukan hubungan interpersonal dengan orang lain akan mengalami gangguan bisa berakibat pada perilaku kurangnya profesionalisme (Keliat, 2016)

Penerapan perilaku Assertiveness merupakan keterampilan penting bagi perawat untuk membentuk kemandirian dan pengembangan, sehingga perilaku asertive merupakan kontrol mengatasi emosi, kesedihan untuk soft skill praktek perawat profesional mengatasi beberapa konflik dalam kesehariannya (Mohamed, Abd El-hammed and Thabet, 2016). Asertive merupakan salah satu cara efektif mencapai kebebasan diri dan rasa kepercayaan diri yang terkandung rasa kepercayaan diri, kebebasan berekspresi secara jujur, tegas, terbuka tanpa mengecilkan ataupun mengesampingkan arti orang lain serta berani bertanggung jawab (Kresna, 2019). Adapun di STIKes Pamenang Prodi Keperawatan pada tahun 2020 yang terdapat 119 mahasiswa dan masih terdapat perilaku mahasiswa yang kurang asertive serta masih ada beberapa yang kurang aktif selama mengikuti proses belajar mengajar karena adanya keluhan harga diri rendah sehingga sangat mempengaruhi motivasi belajar yang berefek terhadap kualitas lulusan.

Penelitian ini bertujuan mengetahui perilaku assertive dan Self Esteem pada mahasiswa keperawatan di STIKes Pamenang Pare Kediri. Hasil penelitian ini akan menjadi informasi penting dalam upaya penerapan asuhan keperawatan jiwa pada pengkajian deteksi gangguan psikososial pada kalangan mahasiswa keperawatan untuk meningkatkan kesehatan jiwa serta perlunya pembinaan mental sehingga di harapkan mampu mencetak persiapan SDM keperawatan unggul mampu bersaing di era MEA. sehingga di harapkan lulusan banyak terserap di lapangan kerja di kancah nasional dan internasional serta dikenal di kalangan masyarakat sehingga meningkatkan minat 
untuk mengikuti pendidikan di STIKes Pamenang Pare Kediri.

\section{Metode}

Penelitian ini merupakan penelitian analitik dengan pendekatan cross sectional dengan uji statistik menggunakan descriptive statistics dan spearman-rho di Stikes Pamenang Pare Kabupaten Kediri pada 01 Januari hingga 30 Febuari 2020. Kemudian data yang terkumpul selanjutnya diolah, ditabulasi dan dilakukan analisis menggunakan software IBM SPSS statistics 20. Subyek penelitian adalah mahasiswa Prodi D3 keperawatan dengan jumlah populasi 119 dengan sample 40, dengan teknik random sampling. Adapun kriteria inklusi adalah mahasiswa keperawatan Prodi D3 keperawatan status aktif dan telah belajar selama lebih 1 tahun di tahun ajaran 20192020 di STIKes Pamenang, kooperatif, adapun kriteria ekslusi adalah mahasiswa yang mengambil cuti di tengah perkuliahan, mahasiswa sakit. Instrument kuesioner baku assertive menggunakan Rathus Assertiveness Schedule (RAS) berjumlah 30 pertanyaan dan self-esteem Rosenberg Self Esteem (RSE) berjumlah 10 pertanyaan, Penelitian ini mempunyai hipotesa $\mathrm{Ho}=$ tidak ada hubungan assertive dengan self-esteem pada mahasiswa Prodi D3 Keperawatan di Stikes Pamenang Pare.

\section{Hasil Dan Pembahasan \\ Assertive}

Tabel 1 Mahasiswa prodi D3 Keperawatan STIKes Pamenang katagori Assertive pada di tahun 2020

\begin{tabular}{|l|l|l|}
\hline Assertive & f & \% \\
\hline Baik & 7 & 18 \\
\hline Sedang & 22 & 55 \\
\hline Kurang & 11 & 27 \\
\hline Total & 40 & 100 \\
\hline
\end{tabular}

Hasil diagram 1 menunjukkan bahwa dari 40 responden sebagian besar adalah terdapat 22 responden (55\%) dengan kategori assertive sedang dikarenakan semua responden masih berada pada masa remaja dengan tahap masih belajar mengelola emosi yang masih labil karena memasuki fase beradaptasi terhadap beberapa perubahan. Adapun akan di jabarkan sebagai berikut.

Assertive adalah perilaku dan suatu proses dimana individu belajar mengkomunikasikan kebutuhan, menolak permintaan, mengekspresikan perasaan positif dan negatif secara terbuka, jujur, langsung, sesuai dengan pemahaman. Individu menggunakan respon asertif mempertahankan haknya serta respek terhadap hak, harkat orang lain (Fortinash, 2003 dalam Keliat, B.A, 2016).

Mayoritas usia responen pada Late adolescence (18-21 tahun) sehingga mengalami periode peralihan dari anak yang cenderung masih ketergantungan menjadi dewasa yang mempunyai tanggung jawab terhadap dirinya maupun masyarakat. Sehingga individu harus meninggalkan segala sesuatu bersifat kekanak-kanakan menjadi harus mempelajari pola perilaku serta sikap baru (Valizadeh et al., 2016).

Individu yang berada di periode peralihan mengalami adaptasi perubahan yang penuh dengan tekanan, sehingga menggunkan mekanisme koping maladaptive menyebabkan stress (Stuart, 2016). Beberapa mahasiswa perawat selama mengikuti masa perkuliahan untuk belajar menjadi perawat secara profesioanal mengalami beberapa peristiwa yang menyebabkan stressor, seperti tekanan hidup bersama orang sekitarnya, jadwal perkuliahan yang padat, tugas kuliah yang menumpuk, praktek lapangan yang berhadapan langsung dengan peristiwa status kesehatan orang lain, proses menghadapi ajal orang lain (Megahed MM, 2014).

Sehingga seseorang yang mengalami stress cenderung beradaptasi menggunakan mekanisme koping adaptip maka individu akan kecenderungan berperilaku asertive, tetapi jika mekanisme koping maladaptive akan mengalami emosi yang labil sehingga menyebabkan assertive dapat menjadi berkurang (Keliat, B.A, 2016).

\section{Self-esteem}

Tabel 2 Mahasiswa prodi D3 Keperawatan STIKes Pamenang dengan karakteristik Self esteem di tahun 2020

\begin{tabular}{|l|l|l|}
\hline Self esteem & f & \% \\
\hline Tinggi & 12 & 30 \\
\hline Sedang & 21 & 53 \\
\hline Rendah & 7 & 18 \\
\hline Total & 40 & 100 \\
\hline
\end{tabular}

Tingkat harga diri rendah pada mahasiswa keperawatan masih dianggap salah satu tantangan paling penting untuk profesi 
keperawatan (Dimitriadou-Panteka A, Koukourikos K, 2014). Harga diri diidentifikasi sebagai faktor penting dalam profesionalisme siswa yang mencakup atributatribut khusus, satu dimensi di antaranya dikaitkan dengan ciri-ciri perilaku. (Björkström ME, Athlin EE, 2008) tampak bahwa atribut profesionalisme lain seperti menjadi ahli atau mengembangkan keterampilan dan pengetahuan dapat dipengaruhi oleh tingkat self esteem mahasiswa (Valizadeh et al., 2016).

Hasil diagram 2 menunjukkan bahwa dari 40 responden sebagian besar adalah terdapat 21 responden $(57,6 \%)$. Dimana self esteem adalah penilaian harga diri pribadi seseorang, berdasarkan seberapa baik perilakunya sesuai dengan ideal diri, dapat diartikan bahwa harga diri menggambarkan sejauh mana individu tersebut menilai dirinya sebagai orang yang memiliki kemampuan, keberartian, berharga, dan kompeten. Seberapa sering seseorang meraih tujuan secara langsung mempengaruhi kompeten (harga diri tinggi) atau rendah diri (harga diri rendah) (Stuart, 2016).

Hasil penelitian ini terdapat hasil yang sama dengan beberapa penelitian lainnya yang melaporkan berkaitan adanya masalah gangguan mental psikososial tingkatan self esteem mahasiwa perawat dengan hasil sebagian besar berada pada level harga diri tingkat sedang (73\%) (Suliman WA, 2007; Furegato AR, Santos JL, 2008; Barkhordary M, Jalalmanesh S, 2009; Azizi M, Khamseh F, Rahimi A, 2013; Megahed MM, 2014). Adapun beberapa penelitian tersebut menjelaskan self esteem siswa memiliki kecenderungan yang meningkat ketika tahun akademik meningkat (Begley CM, 2003).

Adapun hasil penelitian ini bahwa tingkat harga diri rendah pada mahasiswa keperawatan di STIKes Pamenang terdapat $18 \%$. Adapun beberapa penelitian lainnya yang telah di lakukan di luar negeri di Iran mendapatkan hasil 56,1\% mahasiswa keperawatan memiliki harga diri yang rendah ( Azizi M, Khamseh F, Rahimi A, Barati M, 2013).

Terdapat hasil penelitian ini harga diri tinggi pada mahasiswa keperawatan STIKes Pamenang adalah 30\%. Adapun hasil penelitian lainnya dengan hasil hampir $91 \%$ dari siswa memiliki harga diri yang tinggi (Janati Y, Musavi SA, Âzimi Lolaty H, Fani Saberi L, Hamta A, Feyzi S, 2012).

\section{Hubungan Assertiveness Terhadap Self Esteem Pada Mahasiswa Keperawatan di STIKes Pamenang Pare Kediri}

Tabel 3 Tabulasi Silang Assertiveness Terhadap Self Esteem Pada Mahasiswa Keperawatan di STIKes Pamenang Pare Kediri tahun 2020

\begin{tabular}{|c|c|c|c|c|}
\hline \multirow{2}{*}{$\begin{array}{l}\text { Self- } \\
\text { esteem }\end{array}$} & \multicolumn{3}{|c|}{ Assertive } & \multirow{2}{*}{$\begin{array}{l}\text { Tota } \\
1\end{array}$} \\
\hline & Kurang & $\begin{array}{l}\text { Sedan } \\
\mathrm{g}\end{array}$ & Baik & \\
\hline HDR & 5 & 2 & 0 & 7 \\
\hline Sedang & 4 & 15 & 2 & 21 \\
\hline Tinggi & 2 & 5 & 5 & 12 \\
\hline Total & 11 & 22 & 7 & 40 \\
\hline
\end{tabular}

Berdasarkan Tabel 3 tabulasi silang assertiveness terhadap self esteem pada mahasiswa keperawatan di STIKes Pamenang Pare Kediri, data yang terkumpul selanjutnya diolah, ditabulasi dan dilakukan analisis menggunakan software IBM SPSS statistics 20, mendapatkan Sig p value Spearman's rho $=0,003$, koefesien korelasi bernilai positive $=0.462^{* *}$.

Hasil intrepretasi hasil Spearman's rho adalah berdasarkan output tabel 3 di ketahui signifikasi $\mathrm{p}$ value $=0,003$ sehingga $\mathrm{p}$ value $<0,05$, maka ho ditolak, terdapat hubungan assertive dengan self-esteem pada mahasiswa Prodi D3 Keperawatan di Stikes Pamenang Pare. Dengan angka koofisien korelasi sebesar $0.462^{* *}$. berarti tingkat kekuatan hubungan antara dua variabel adalah sebesar $0.462^{* *}$. korelasi hubungan cukup. Dengan angka koofesien bernilai positive adalah $0.462^{* *}$. Hubungan antara kedua variabel penelitian ini bersifat hubungan searah, dengan demikian dapat diartikan bahwa assertive semakin baik maka akan terbentuk self-esteem yang tinggi.

Dapat di simpulkan ho ditolak dan Ha di terima adalah berarti ada hubungan signifikan yang cukup kuat dan searah antara hubungan assertive dengan self-esteem pada mahasiswa Prodi D3 Keperawatan di STIKes Pamenang Pare. Temuan investigasi ini menunjukkan bahwa perilaku asertif dan harga diri berkorelasi positif dan signifikan. Perawat harus secara teratur menilai perilaku asertif mereka sebagaimana adanya mempengaruhi harga diri. Kemungkinan alasan adanya 
berkorelasi untuk positif yaitu orang yang asertif mampu mempertahankan kondisi mental positif. Karena hubungan antara perilaku asertif dan harga diri yaitu orang yang asertif cenderung mengalami tingkat psikologis yang lebih tinggi, sehingga dapat mengontrol emosi dengan baik sehingga dapat berperilaku dengan baik selama mengikuti pendidikan keperawatan sehingga menghasilkan lulusan yang profesional dalam bidang keperawatan (S. K. Maheshwari, 2015).

Perilaku asertif terhadap harga diri sebagai salah satu permasalahan utama dalam profesi keperawatan. Perawat dengan perilaku asertif tinggi dengan harga diri tinggi cenderung dapat memberikan perawatan pasien secara terapeutik sehingga sangat berkaitan erat dengan tindakan profesional selama menjalankan keperawatan.

\section{Kesimpulan}

Hasil penelitian ini telah dilakukan deteksi dini pada responden dengan masalah gangguan jiwa psikosial adalah perilaku Assertive sedang 22 (55\%), kurang 11 (28\%), baik 7 (18\%). Dan konsep diri pada Self esteem adalah sebagian besar sedang 21 $(53 \%)$, dan harga diri tinggi $12(30 \%)$, dan harga diri rendah 7 (18\%).

Hasil penelitian ini adalah ada hubungan signifikan yang cukup kuat dan searah antara hubungan assertive dengan self-esteem pada mahasiswa Prodi D3 Keperawatan di STIKes Pamenang Pare. Dikarenakan self esteem adalah penilaian harga diri pribadi seseorang, berdasarkan seberapa baik perilakunya sesuai dengan ideal diri, sejauh mana individu tersebut menilai dirinya yang memiliki kemampuan, keberartian, berharga, dan kompetensi yang dapat mempengaruhi perawat bertindak profesional. Sehingga semenjak proses di pendidikan perlu di siapkan pengelolaan teknik aplikasi assertiveness yang efektif untuk penatalaksanaan peningkatan self esteem pada mahasiswa keperawatan sehingga bisa menghasilkan lulusan SDM perawat yang unggul.

\section{Saran}

1. Institusi pendidikan STIKes Pamenang Prodi D3 Keperawatan sebagai tempat pendidikan di upayakan untuk segera di berikan tindakan konseling dan terapi pendekatan kesehatan mental psikosial pada mahasiswa yang telah terdeteksi mengalami gangguan psikosial katagori assertive kurang $27 \%$ dan low self esteem 18\%. Dan mahasiswa keperawatan selama mengikuti kegiatan proses pendidikan bisa divariasikan dengan pengenalan aplikasi pengelolaan assertiveness yang efektif sehingga mahasiswa lebih bersikap adaptive yang secara langsung dapat berdampak pada peningkatan low self esteem.

2. Peneliti selanjutnya diharapkan dapat melakukan penelitian kualitatif tentang assertive dan self esteem pada mahasiswa keperawatan.

\section{Daftar Pustaka}

Azizi M, Khamseh F, Rahimi A, B. M. (2013) 'The relationship between self-esteem and depression in nursing students of a selected medical university in Tehran. Iranian Journal of Psychiatric Nursing', Iranian Journal of Psychiatric Nursing, 1(1), pp. 28-34.

Barkhordary M, Jalalmanesh S, M. M. (2009) 'The relationship between critical thinking disposition and self esteem in third and forth year bachelor nursing students', Iranian Journal of Medical Education., 9(1), pp. 1319.

Begley CM, W. P. I. . (2003) 'Nursing students' changing self-esteem and fear of negative evaluation during their preregistration programme', J Adv Nurs, 42(4), pp. 390-401.

Björkström ME, Athlin EE, J. I. (2008) 'Nurses' development of professional self--from being a nursing student in a baccalaureate programme to an experienced nurse', J. Clin Nurs, 17(10), pp. 1280-1391.

Chaves Cássia Lopes, E. et al. (2012) 'Assessment of nursing students' self-esteem at a university in the South of Minas Gerais (Brazil)', Aticulo Original, 30(3), pp. 261269. doi: 10.1016/j.electacta.2013.10.065.

Dimitriadou-Panteka A, Koukourikos K, P. (2014) 'The concept of self-esteem in nursing education and its impact on professional behavior', International Journal of Caring Sciences, 7(1), pp. 40-395.

Furegato AR, Santos JL, S. E. (2008) 'Depression among nursing students associated to their self-esteem, health perception and interest in mental health', Rev Lat Am Enfermagem, 16(2), pp. 198-204.

Janati Y, Musavi SA, Âzimi Lolaty H, Fani Saberi L, Hamta A, Feyzi S, et al (2012) 'Investigating emotional intelligence and self esteem level among nursing and midwifery students of Mazandaran University of Medical Sciences in 2010', Journal of Mazandaran University of Medical Sciences, 
21(1), pp. 254-261.

Keliat, B.A, D. (2016) Program Studi Ners Spesialis I Keperawatan Jiwa Fakultas Ilmu Keperawatan Universitas Indonesia. Program Studi Ners Spesialis I Keperawatan Jiwa Fakultas Ilmu Keperawatan Universitas Indonesia

Keliat, B. A. (2016) Modul keperawatan jiwa. Depok.

Kresna (2019) Pengertian mahasiswa keperawatan (skripsi dan tesis), 29 Maret.

Megahed MM, M. F. (2014) 'Effect of cooperative learning on undergraduate nursing students' self-esteem', J. Nurs Educ Pract, 4(11), pp. 13-19.

Mohamed, N. A., Abd El-hammed, N. A. and Thabet, R. A. (2016) 'The Effect of Assertiveness Training Program on Psychiatric Nurses' Communication Skills and Self-Esteem', Med. J. Cairo Univ, 84(1), pp. 663-669.

Nursalam. Effendi, F. (2014) Pendidikan Dalam Keperawatan Nursalam Ferry Efendi.

Parandavar, N., Rahmanian, A. and Badiyepeymaie Jahromi, Z. (2015) 'A Study of the Relationship Between Nurses' Professional Self-Concept and Professional Ethics in Hospitals Affiliated to Jahrom University of Medical Sciences, Iran', Global Journal of Health Science, 8(4), p. 82. doi: 10.5539/gjhs.v8n4p82.

Ristekdikti (2017) Uji kompetensi nasional tenaga kesehatan tingkatkan standarisasi lulusan dan daya saing.

S. K. Maheshwari, K. K. G. (2015) 'Relationship of Assertiveness and Self Esteem among Nurses.', International Journal of Health Sciences and Research (IJHSR), 5(6), pp. 440-449.

Stuart, G. . (2016) Prinsip dan praktik keperawatan jiwa Stuart (terjemahan) Jilid 1 \& 2. Singapore: Elsevier.

Suliman WA, H. J. C. (2007) 'Critical thinking, self-esteem, and state anxiety of nursing students', Nurse Educ Today, 27(2), pp. 162168.

Valizadeh, L. et al. (2016) 'Self-esteem challenges of nursing students: an integrative review', Research and Development in Medical Education, 5(1), pp. 5-11. doi: 10.15171/rdme.2016.003. 